\title{
International Consensus on Guiding Recommendations for Management of Patients with Nonsteroidal Anti- inflammatory Drugs Induced Gastropathy-ICON-G
}

\begin{abstract}
${ }^{1}$ Richard Hunt, ${ }^{2}$ Leonid B Lazebnik, ${ }^{3}$ Yury C Marakhouski, ${ }^{4}$ Mircea Manuc, ${ }^{5}$ Ramesh GN, ${ }^{6}$ Khin S Aye, ${ }^{7}$ Dmitry S Bordin, ${ }^{8}$ Natalia V Bakulina, ${ }^{9}$ Baurzhan S Iskakov, ${ }^{10}$ Abror A Khamraev, ${ }^{11}$ Yurii M Stepanov, ${ }^{12}$ Reidwaan Ally, ${ }^{13}$ Amit Garg

${ }^{1}$ Department of Medicine, McMaster University Health Science Centre, Hamilton, Ontario, Canada, ${ }^{2}$ Hospital Therapy, Moscow State University of Medicine and Dentistry, Moscow, Russian Federation, ${ }^{3}$ Department of Gastroenterology and Nutrition, Belarusian Medical Academy of Postgraduate Education, Minsk, Belarus, ${ }^{4}$ Clinic of Gastroenterology and Hepatology, Fundeni Clinical Institute, Bucharest, Romania, ${ }^{5}$ Centre of Excellence in Gastroenterology and Integrated Liver Care Aster Medi City, Cochin, Kerala, India, ${ }^{6}$ Department of Gastroenterology, University of Medicine, Yangon, Yangon Region, Myanmar, ${ }^{7}$ Department of Pancreatic, Biliary tract and Upper GI disease, A.S. Loginov Moscow Clinical Scientific Center, Moscow, Russian Federation, ${ }^{8}$ Department of Therapy and Clinical Pharmacology, North-Western State Medical University, Sankt-Peterburg, Russian Federation, ${ }^{9}$ Department of Healthcare, Almaty Health Authority, Almaty, Almaty Province, Kazakhstan, ${ }^{10}$ Department of Gatroenterology, Tashkent Medical Academy, Tashkent, Tashkent Province, Uzbekistan, ${ }^{11}$ Institute of Gastroenterology of National Academy of Medical Sciences of Ukraine, Dnipropetrovsk Dnipropetrovsk Oblast, Ukraine, ${ }^{12}$ Department of Gastroenterolgy, Wits University, Johannesburg, Gauteng, South Africa, ${ }^{13}$ Department of Emerging Markets, Dr Reddy's Laboratories Ltd, Hyderabad, Andhra Pradesh, India
\end{abstract}

\begin{abstract}
Introduction: Nonsteroidal anti-inflammatory drugs (NSAIDs), one of the most commonly used medications worldwide, are frequently associated with gastrointestinal adverse events. Primary care physicians often face the challenge of achieving adequate pain relief with NSAIDs, while keeping their adverse events to a minimum. This is especially true when long-term use of NSAIDs is required such as in patients with osteoarthritis and rheumatoid arthritis. To help primary care physicians deal with such challenges more effectively, a panel of expert gastroenterologists came together with the aim of developing practice recommendations.
\end{abstract}

Methods: A modified 'Delphi' process was used to reach consensus and develop practice recommendations. Twelve gastroenterologists from nine countries provided their expert inputs to formulate the recommendations. These recommendations were carefully developed taking into account existing literature, current practices, and expert opinion of the panelists.

Results: The expert panel developed a total of fifteen practice recommendations. Following are the key recommendations: NSAIDs should be prescribed only when necessary; before prescribing NSAIDs, associated modifiable and non-modifiable risk factors should be considered; $H$. pylori infection should be considered and treated before initiating NSAIDs; patients should be properly educated regarding NSAIDs use; patients who need to be on long-term NSAIDs should be prescribed a gastroprotective agent, preferably a proton pump inhibitor and these patients should be closely monitored for any untoward adverse events.

Conclusion/clinical significance: These practice recommendations will serve as an important tool for primary care physicians and will guide them in making appropriate therapeutic choices for their patients.

Keywords: Gastropathy, Gastroprotective agents, Non-prescription drugs, Nonsteroidal Anti-inflammatory Agents, Proton pump inhibitor.

How to cite this article: Hunt R, Lazebnik LB, Marakhouski YC, Manuc M, Ramesh GN, Aye KS, Bordin DS, Bakulina NV, Iskakov BS, Khamraev AA, Stepanov YM, Ally R, Garg A. International Consensus on Guiding Recommendations for Management of Patients with Nonsteroidal Anti-inflammatory Drugs Induced Gastropathy-ICON-G. Euroasian J Hepatogastroenterol, 2018;8(2):148-160.

\section{Source of support: Nil}

Conflict of interest: Richard Hunt has served as a consultant for INSYS, Dr Reddy's, Takeda, and Novartis. He has received an honorarium from Novartis, Danone, Dr Reddy's, and Takeda. He has been on the speaker's bureau for Takeda and Dr Reddy's and on scientific advisory board for INSYS. Dmitry S Bordin has served as a lecturer for Astellas, AstraZeneca, KRKA and Abbott. For the remaining authors, there are no conflicts of interest.

Address reprint request to: Amit Garg, Department of Emerging Markets, Dr Reddy's Laboratories Ltd, Hyderabad, Andhra Pradesh, India, e-mail: amitgarg.pharm@gmail.com, 


\section{BACKGROUND}

Nonsteroidal anti-inflammatory drugs (NSAIDs) are used by over 30 million people daily across the globe. ${ }^{1}$ The use of NSAIDs has become widespread due to the availability of these agents both as prescription and as over-the-counter (OTC) medicines. ${ }^{2}$ Even though NSAIDs have proven efficacy in managing pain, fever, and inflammation, they are frequently associated with several untoward adverse events (AEs). ${ }^{3}$ While NSAIDs are also associated with renal (fluid retention, hyperkalemia, secondary hypertension) and cardiovascular (vascular events, hypertension) AEs, the most common are gastrointestinal (GI) complications, which includegastritis, ulcers, perforation, and enteropathy. ${ }^{3,4} \mathrm{~A}$ study from Denmark reported an increase in the prevalence of NSAID-related peptic ulcers from 39\% in 1993 to $53 \%$ in 2002. ${ }^{5}$ Further, the point prevalence of GI complications related to NSAID exposure in the Indian subcontinent in the year 2014 was found to be $30 \% .{ }^{6}$ Overall, mortality in patients suffering from an upper gastrointestinal (UGI) bleed or perforation related to NSAIDs use is estimated to be about 1 in $5 .^{7}$ Additionally, the prevalence of gastroduodenal ulcers in patients taking low-dose aspirin (LDA) is about $10 \%{ }^{8}$

The NSAID-induced gastropathy (NIG) develops at doses that inhibit prostaglandin production, enhance gastric motility, and increase mucosal permeability. This results in neutrophil infiltration and free radical production, and eventually mucosal lesions. ${ }^{9}$ Risk factors include increasing age, the presence of comorbidities especially a history of peptic ulcer disease, liver cirrhosis, and cardiovascular disease. Long-term use of NSAIDs, Helicobacter pylori (H. pylori) infection, smoking, chronic alcohol abuse, and concomitant use of other medications increase the risk of developing NIG. ${ }^{3,10-13}$

The NSAIDs have remained the first-line for controlling pain and inflammation particularly in patients with osteoarthritis (OA). Complete withdrawal from NSAIDs is not always practical, particularly in patients with chronic musculoskeletal disorders. Therefore, it is important that clinicians prescribe NSAIDs wiselyto ensure maximum benefits and minimize AEs. All healthcare practitioners, particularly primary care physicians $(\mathrm{PCP})$ can reduce the risk of NIG by careful patient assessment and identification of the risk factors before prescribing an NSAID, educating patients against the addition of OTC NSAIDs, using selective cyclooxygenase-2 (COX-2) inhibitors as first-line medications where appropriate, and co-therapy with a gastroprotective agent (GPA). ${ }^{1,3,9}$

Several international and regional guidelines have been developed to manage NSAID-induced GI complica- tions. ${ }^{10-17}$ However, none specifically focus on management of NIG highlighting the need for a comprehensive clinical guidelineto guide PCPs in the management of NIG, particularly in resource-limited regions of the world. This article presents practice recommendations primarily targeted towards primary care providers, for prevention, early detection, and management of NIG formulated at a meeting held in Dubai, UAE on December 1st, 2016.

\section{OBJECTIVE}

The objective of this consensus meeting was to identify the advances in disease management and the opportunitiesfor prevention and management of NIG in nine nations. Further, we attempted to develop definitive clinical practice guidelines for the management of patients with NIG based on the existing literature, real-world evidence, and evidence-based practice.

Ameeting was held before the International Congress of GI Experts, Gastrosphere 2.0 (in Dubai, UAE) in association with the healthy stomach initiative (HSI). The committee of experts from nine nations was named the ICON-G group. Expert representatives proposed recommendations for use by PCPs and internists in the prevention, identification, and management of NIG.

\section{METHODS}

A modified Delphi consensus process (Fig. 1) was implemented to develop the recommendations. ${ }^{18,19}$ Literature was searched to provide evidence, and recommendations were developed by combining evidence-based and expert consensus-based approach. A comprehensive methodology and transparency in reporting were adopted to develop these clinical practice recommendations.

The process was conducted in two phases. Phase one included an online survey and literature search. The online survey(on online portal survey monkey. com) included twenty questions to establish the current clinical practice in the nine countries. The responses collected from the survey were then used to quantify theknowledgeand practice gap in each of the countries.

An electronic literature search was conducted in PubMed and MEDLINE. The search strategy was developed by combining Medical Subject Headings (MeSH) and free-text keywords using Boolean operators ('OR' and 'AND'). Keywords used were "nonsteroidal antiinflammatory drugs", "NSAIDS", "gastropathy", "gastritis", "ulcers", "gastric bleeding", "gastric complications", and "gastroprotective agents". Relevant literature from published clinical studies, narrative reviews, systematic reviews, and meta-analyses was collected through September 2016. No additional filters were used during 


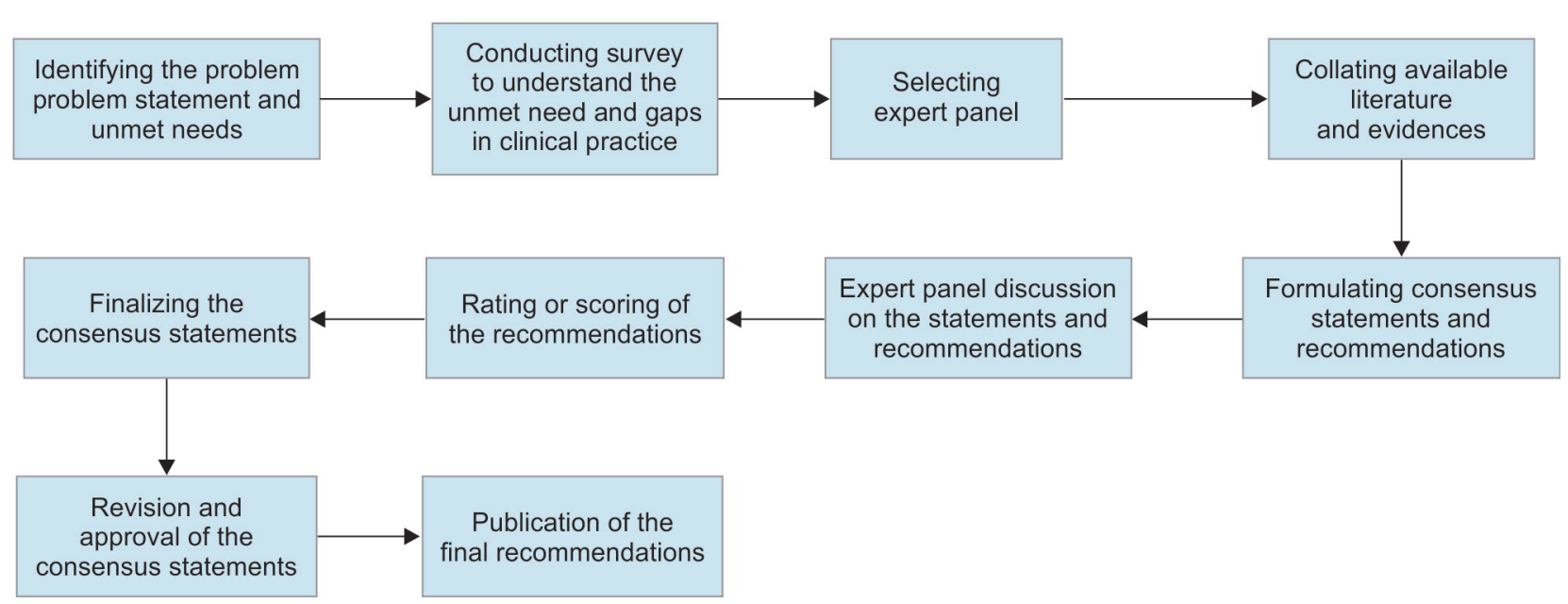

Fig. 1: Modified Delphi protocol for consensus development

the search. An extensive manual search of literature references was also done, and relevant articles retrieved. Several published international and regional clinical practice guidelines on the management of GI complications were also retrieved. ${ }^{10-17} \mathrm{All}$ the available literature and evidence were collated and developed into practice recommendations. These were discussed at the meeting and categorized according to the level of evidence.

In phase two, core-committee of ICON-G members comprising of a chairperson and twelve expert gastroenterologists from Russia, India, Romania, Ukraine, South Africa, Kazakhstan, Belarus, Uzbekistan, and Myanmar, with knowledge and experience of NSAID-induced GI injury, was formed. A pre-meeting draft depicting the purpose of the guidelines, the target patient population, clinical outcomes of interest, key features of the systematic literature review, and a proposed timeline for guideline completion was shared with all panel members. An advisory board meeting chaired by Professor Richard Hunt was conducted with the core-committee of ICON-G on December 1st, 2016 in Dubai (UAE), to discuss and establish the process for the consensus guideline development.

On December 3rd, 2016, the members of Consensus Group (i.e., members of core-committee of ICON-G together with delegates attending the International Congress of GI Experts) discussed and rated their agreement for each recommendation on a four-point Likert scale. Open discussion was conducted for each recommendation, considering evidence and rationale. Voting then took place. About $60 \%$ of the voters were gastroenterologists, and $40 \%$ were general physicians, with extensive experience of delivering patient care across a wide range of specialties relevant to primary care. The core-committee determined the strength of agreement for each recommendation as follows:

- Strong Consensus: If $\geq 90 \%$ of respondents rated the recommendation as "strongly agree" and/or "agree"
- Consensus: If $\geq 80 \%$ and $<90 \%$ of respondents ratedthe recommendation as "strongly agree" and/or "agree"

- No Consensus: If $<80 \%$ of the respondents rated the recommendation as "strongly agree" and/or "agree"

\section{PRACTICE RECOMMENDATIONS}

\section{Practice Recommendation 1}

The NSAID prescription is associated with a high-risk of NIG.

(Consensus: Vote; strongly agree $76 \%$, agree $24 \%$ )

\section{Rationale}

Studies have shown that NSAIDs are associated with gastropathy irrespective of the duration of use.

The evidence study ( $\mathrm{N}=4144)$ was the largest prospective study of the real-life management of European patients treated with NSAIDs for rheumatic diseases, who wereat an increased GI risk due to advanced age $(\geq 60$ years), history of peptic ulcer, or concomitant therapy (corticosteroids, anticoagulants). ${ }^{20}$ The study found that NSAIDs were associated with an incidence of 18.5 per 100 person-years for uncomplicated GI events and 0.7 per 100 person-years for complicated GI events. During a median follow-up of 6 months, UGI events (12\%) were more common than the lower GI events $(1 \%){ }^{20}$

A systematic review $(\mathrm{N}=19841)$ reported that the risk of developing serious NSAID-related GI events is essentially constant over time. ${ }^{21}$ A large autopsy series on patients with a history of NSAID use found a slightly higher number of nonspecific ulcers in the small intestine in long-term NSAID users, and a slightly higher number ofgastric ulcersin short-term NSAID users when compared to long-term users. ${ }^{22}$

A nested case-control study found that, compared to non-users, current NSAID users are at a higher risk of developing serious UGI complications by a factor of 
3.7 [95\% confidence interval (CI ), 3.1-4.3], and selective COX-2 inhibitors by a factor of $2.6(95 \% \mathrm{CI}, 1.9-3.6) .{ }^{23}$ This study also foundthat short- and long-term NSAIDs use was associated with a similar risk of UGI complications. Similar findings were reported inother meta-analyses where the relative risk (RR) of serious GI complications was found to be 3 to 4 fold higher in NSAID users compared with non-users irrespective of the duration of use. ${ }^{24-26}$

A multicenter study $(\mathrm{N}=187)$ reported a high point prevalence rate for ulcers (10.7\%) and erosions (63.1\%) in patients taking LDA. After a follow-up of 3 months $(\mathrm{N}=113)$ the incidence of ulcers anderosions was $7.1 \%$ and $60.2 \%$, respectively, suggesting ulcers developed in almost 1 in 10 LDA users. ${ }^{27}$ A meta-analysis $(\mathrm{N} \sim 66000)$ to assess the incidence of GI hemorrhage associated with aspirin therapy showed that long-term ( $\geq 12$ months) aspirin treatment was associated with a significant increase in the incidence of GI bleeding. Bleeding was reported in $2.47 \%$ of patients taking aspirin compared with $1.42 \%$ taking a placebo [odds ratio (OR) $1.68 ; 95 \%$ CI,1.51-1.88]. ${ }^{28}$

\section{Practice Recommendation 2}

All NSAIDs, irrespective of their route of administration, have the potential to NIG.

(Consensus: Vote; strongly agree 64\%, agree 34\%, disagree $2 \%)$

\section{Rationale}

Although topical NSAIDs are generally safer than oral NSAIDs withfewer severe GI AEs, $17.5 \%$ of patients receiving topical NSAIDs in onestudy reported systemic AEs. Topical NSAIDs potentiated warfarin in five cases, leading to GI bleeding in one case. ${ }^{29}$

A meta-analysis comparing the safety profile of different types of NSAIDs confirmed the variability inRR among various NSAIDs. ${ }^{30}$ Irrespective of the type and formulation, all NSAIDs were associated with GI AEs. The lowest RR was observed with aceclofenac, celecoxib, and ibuprofen, and the highest with piroxicam, ketorolac, and azapropazone. Rofecoxib, sulindac, diclofenac, meloxicam, nimesulide, ketoprofen, tenoxicam, naproxen, indomethacin, and diflunisal were associated with moderate risks. ${ }^{30}$ In another meta-analysis, nabumetone was associated with a very low GI risk when compared to other NSAIDs $(p=0.007){ }^{31}$

Somenovel NSAID formulationsare safer compared to the conventional forms. A meta-analysis of randomized controlled trials (RCTs) concluded that AMG is an effective anti-inflammatory drug with an improved GI tolerability profile, and lower incidence of GI AEs compared to traditional NSAIDs. The endoscopy scores were higher for other NSAIDs than AMG (27.6\% versus $21.4 \%$; $\mathrm{p}<0.05)$. Likewise, post-treatment severity of gastric and/ or duodenal ulcer was higher in the NSAID group than AMG group $\left(14.2 \%\right.$ vs. $4.3 \%$; p<0.05).$^{32}$

\section{Practice Recommendation 3}

The most common non-modifiable risk factors for NIG includeage ( $>60$ years), a prior history of peptic ulcers, and complications such asa history of gastrointestinal bleeding.

(Consensus: Vote; $65 \%$ strongly agree, 33\% agree, 2\% disagree)

\section{Rationale}

Age is one of the strongest predictors of NSAID related GI complications. A large prospective multicenter study in rheumatoid arthritis (RA) patients $(\mathrm{N}=2747)$ found that the principal risk factors $(\mathrm{p}<0.05)$ were increasing age, a history of NSAID-related ulcer and its complications, and corticosteroid use. ${ }^{33}$ Similarly, another study reported that age $>60$ years (OR, 5.52; 95\% CI, 4.63-6.60) and previous history of GI complications (OR, 4.76; $95 \%$ CI, 4.05-5.59)were associated with an increased risk for serious GI AEs. ${ }^{21}$

Another study reported that the risk for serious NSAID induced GI eventswas nearly doubled with each of the following factors: a history of previous GI events, peptic ulcer, concomitant glucocorticoid treatment, and severe arthritis induced disability. Using multiple drugs, changing the NSAID, or using high dosesincreasedthe risk by at least 6 -fold. Age $>65$ years and a history of cardiovascular disease increased the risk by 2 to 3 fold. The presence of multiple risk factors also increased the incidence of GI complications during NSAID therapy. ${ }^{34}$

Although increasing age is a major risk factor for NSAID-induced GI complications, these problems are also seen in the pediatric population. In a retrospective, multicenter study of Italian children $(\mathrm{N}=51)$ attending the emergency unit with GI bleeding following NSAIDs use, $62 \%$ of patients had endoscopically confirmed gastric lesions, 33\% had duodenal lesions, and 15\% had esophageal lesions. Of particular concern, $6 \%$ required endoscopic hemostasis to control GI bleeding. These findings emphasize that children are also vulnerable to NSAID-induced gastric complications. ${ }^{35}$

\section{Practice Recommendation 4}

The modifiable risk factors for NIG include concomitant use of aspirin and/or other NSAIDs, systemic corticosteroids, 
anticoagulants/antiplatelet, and selective serotonin reuptake inhibitors (SSRIs).

(Consensus: Vote; strongly agree 59\%, agree 37\%, disagree $4 \%)$

\section{Rationale}

Results from the Italian pharmaco vigilance reporting system show that the combined use of LDA and another NSAID or use of multiple NSAIDs is associated with an increased incidence of GI adverse events. ${ }^{36}$ Further, the Spanish safe prescription recommendations emphasize that two or more NSAIDs simultaneously do not increase effectiveness but do increase toxicity. ${ }^{37}$

A meta-analysis summarized the results from 16 studies reporting an almost twofold increase in the risk of serious GI complications when NSAIDs were used concomitantly with corticosteroids compared to NSAIDs alone (OR, 1.83; CI, 1.20-2.78). ${ }^{21}$

A case-control study from the National Health System in Spain reported that concomitant use of NSAIDs with clopidogrel/ticlopidine (RR, 15.2; 95\% CI, 4.1-56.5)oranticoagulants (RR, 19.3; 95\% CI 8.2-45.3) increased the risk of UGI bleeding substantially. ${ }^{38}$ Similarly, in another casecontrol study from the United Kingdom General Practice Research Database, combining NSAIDs with clopidogrel (RR, 2.93; 95\% CI, 1.74-4.93) or warfarin (RR, $4.60 ; 95 \%$ CI, 2.77-7.64) was associated with an increased risk of GI bleeding. ${ }^{39}$ Another study found that combined use of an NSAID with LDA (OR, 4.3; 95\% CI, 1.7-11; $\mathrm{p}<0.01)$ or other antiplatelet drugs (OR, 4.9; 95\% CI, 1.4-17; $\mathrm{p}=0.01)$ was associated with a greater risk of lower GI bleeding than when used alone (OR, 2.3; 95\% CI, 1.6-3.2; $\mathrm{p}<0.01)$. Furthermore, a combination of NSAIDs was associated with a higher risk than use of a single NSAID (OR, 4.9; 95\% CI, 2-12; $\mathrm{p}<0.01) .{ }^{40}$

A population-based retrospective cohort study reported that there could be up to a $50 \%$ increase in the risk of GI bleeding with dabigatran compared with warfarin and a more than the twofold higher risk of bleeding with rivaroxaban compared with warfarin. ${ }^{41}$ Combining these newer antiplatelet drugs with NSAIDs carries a definite increased GI risk of bleeding.

Selective serotonin reuptake inhibitors may also lead to GI bleeding when given with NSAIDs, by impairing the metabolism of NSAIDs leading to an increase in their blood levels,and also by inhibiting hemostasis. ${ }^{42,43} \mathrm{~A}$ systematic review showed that the RR for UGI bleeding from NSAID and SSRI combination compared to use of neither drug was 3.3-15.6 and that for GI AEs was 12.4. ${ }^{44}$ A case-control study showed a moderate increase in UGI risk with concurrent use of SSRIs and NSAIDs when com- pared to NSAIDs use alone (OR, 1.57; 95\% CI, 1.24-1.99) and higher increase, when compared to use of neither drug (OR, 4.19; 95\% CI, 3.30-5.31). ${ }^{45}$ Similar results, were found in several other studies where the combined use of NSAIDs and SSRIs was associated with an OR of about 4 for GI AEs. ${ }^{46,47}$

\section{Practice Recommendation 5}

H. pylori infection increases the risk of developing NIG. It is suggested that physicians consider the possibility of $H$. pylori infection and treat it, if present, prior to prescribing NSAIDs.

(Consensus: Vote; strongly agree $58 \%$, agree $38 \%$, disagree $4 \%)$

\section{Rationale}

H. pylori infection together with the use of NSAIDs is a well-known risk factor that induces gastroduodenal mucosal damage and ulcers. ${ }^{48} \mathrm{~A}$ meta-analysis found that NSAIDs and $H$. pylori infection are not only independent risk factors, but they also have a synergistic effect on the development of peptic ulcer and ulcer bleeding. ${ }^{49}$ While the risk of ulcer bleeding increased 1.79 -fold with $H$. pylori infection and 4.85-fold with NSAID use, the two together increased the risk 6.13-fold. ${ }^{49}$ In a systematic review of 21 studies $(\mathrm{N}=10146)$, the peptic ulcer was more common in NSAID users who were $H$. pylori positive (OR, 1.81; $95 \%$ CI, $1.40-2.36) .{ }^{50}$ Furthermore, in a meta-analysis of RCTs, $7.4 \%$ of patients developed an ulcer in the H. pylori eradicated group compared with $13.3 \%$ in the control group (OR, 0.43; 95\% CI, 0.20-0.93). ${ }^{51} \mathrm{~A}$ recent retrospective study of 245 patients taking an NSAID or LDA continuously for at least 3 months reported that presence of $H$. pylori infection increases the risk of severe gastric mucosal injury (OR, 2.0; 95\% CI, 1.2-3.5). ${ }^{52}$

All these studies highlight that NSAIDs and H. pylori infection synergistically cause gastric mucosal injury. However, H. pylori testing may not be practical for all patients especially in the primary care setting. ${ }^{53}$ Testing must be carried out when the patient is prescribed longterm NSAIDs in areas where H. pylori are common. In current practice, $H$. pylori eradication therapy comprises of PPIs and antimicrobials agents, including bismuth compounds, clarithromycin, amoxicillin, metronidazole, levofloxacin, furazolidone, doxycycline, nitazoxanide, andrifabutin. ${ }^{54,55}$

\section{Practice Recommendation 6}

It is suggested that physicians consider prescribing NSAIDs only when indicated.

The prescribing physician should consider patientspecific risk factors before prescribing NSAIDs. 
(Consensus: Vote; strongly agree 69\%, agree 29\%, disagree $2 \%$ )

\section{Rationale}

Clinicians must identify NSAIDs use as a risk factor for GI complications and initiate preventive treatment. A population-based cohort study showed that despite the risk of UGI events, guidelines for GPA use were followed in less than half of the cases. GPAs were prescribed in $31.8 \%$ of high-risk patients receiving LDA and $48.0 \%$ of those receiving NSAIDs. ${ }^{56}$ Similarly, the Canadian Osteoarthritis Rx (CANOAR) study examined NSAID use in clinical practice in a cohort of PCPs and compared it with the osteoarthritis treatment guidelines. Overall, $58 \%$ of the prescriptions were found to be appropriate considering the GI risk of the patients. ${ }^{57}$ Thus, there is an opportunity for improvement in implementing strategies by adherence to guidelines. ${ }^{56,57}$

A RCT evaluated a physician education program, communicating OA management guidelines in elderly patients, which emphasized avoidance of NSAIDs. Physicians ( $N=209$ ) were visited with reminders for a re-evaluation of their patients' NSAIDs. Brief physician educational visits resulted in a 7\% (95\% CI, 3-11\%) reduction in NSAIDs use without undesirable substitution of other medications or detectable worsening of musculoskeletal symptoms. ${ }^{58}$

A Korean observational study of NSAID prescription patterns in orthopedic patients highlighted the need for better understanding of patient-specific risk factors among prescribing physicians. The study showed that, despite being identified as high-risk or at very high GI risk (by a risk scoring scale), only $51 \%$ of patients were given a COX-2 selective inhibitor instead of a traditional NSAID. Physician's preference for a particular NSAID and not considering a patient's GI risk factors may expose patients to increased risk of NSAID-induced GI complications. $^{59}$

\section{Practice Recommendation 7}

It is recommended that the prescribing physician educates the patient against self-medication with NSAIDs and the importance of regular follow-up, particularly in those on long-term and/or high-dose NSAIDs.

(Consensus: Vote; strongly agree $54 \%$, agree $41 \%$, disagree $4 \%$ )

\section{Rationale}

When the prescribed NSAIDs do not adequately control pain, patients may often seek additional OTC NSAIDs. ${ }^{60}$ They may not be aware that OTC pain-relief medications belong to the same class as their prescribed NSAIDs, resulting in high dose NSAID treatment. Patients may thus increase their risk of developing GI complications. In one study, total $26 \%$ of the participants were users of two NSAIDs and had poorer health-related quality of life (QoL) compared to those not on high doses of NSAIDs. ${ }^{60}$ A cross-sectional study, conducted in the Netherlands, assessed the prevalence of OTC-NSAID use in a sample of the general population $(\mathrm{N}=118)$ and in a sample of patients $(\mathrm{N}=264)$ with a high risk of developing serious NSAID-related AEs. ${ }^{2}$ The results of this study showed high and unregulated use of NSAIDs. OTC NSAIDs were used by $30 \%$ of the general population and $13 \%$ of the high-risk sample. OTC NSAIDs dose exceeded the recommended daily maximum by $9 \%$ and $3 \%$ in the general population and high-risk sample respectively. ${ }^{2}$ Proper patient education, is, therefore, of the utmost importance.

Patients must also be informed about the importance of adherence to GPAs. One study evaluated the association between adherence to GPA and UGI events among NSAID users. Among those who were non-adherent, the OR was 2.39 (95\% CI, 1.66-3.44) for all UGI events and 1.89 (95\% CI, 1.09-3.28) for UGI bleeding alone, compared to those who adhered fully, emphasizing the importance of implementing strategies to follow and improve GPA adherence. $^{61}$

\section{Practice Recommendation 8}

In patients on long-term NSAID treatment, regular and patient-specific monitoring (with due consideration to comorbidities, other medications, and the presence of all risk factors) is recommended for evidence of gastrointestinal bleeding and/or gastrointestinal side-effects. (Consensus: Vote; strongly agree $67 \%$, agree $27 \%$, disagree $4 \%$, strongly disagree $2 \%$ )

\section{Rationale}

Scarpignato and Hunt (2010) suggested that physicians should not prescribe NSAIDs before taking a careful history and undertaking a physical examination, to evaluate patient-specific risks and benefits for NSAID therapy. ${ }^{62}$ Furthermore, in the presence of GI and/or cardiovascular risk factors, appropriate preventive strategies (i.e., COX-2 selective inhibitors and/or PPI use as well as the need for LDA) should be implemented from the start of treatment with compliance assessed regularly, especially in high-risk patients. ${ }^{62}$

\section{Practice Recommendation 9}

Co-therapy with a PPI is the preferred approach for prevention of NIG. Alternatively, a histamine-2 receptor antagonist (H2RAs) or misoprostolcan be used.

(Consensus: Vote; strongly agree $84 \%$, agree $14 \%$, disagree $2 \%)$ 


\section{Rationale}

A systematic reviewand meta-analysis emphasized the superiority of PPI therapy over H2RA or placebo in reducing mortality among patients with an endoscopically confirmed high-risk of peptic ulcer bleeding. PPI therapy also reduced rates of re-bleeding and the need for surgical intervention. ${ }^{63}$

In a meta-analysis including $10 \mathrm{RCTs}(\mathrm{N}=8780)$, PPIs reduced the risk of LDA-associated UGI ulcers $(\mathrm{OR}=$ 0.16 ; $95 \% \mathrm{CI}, 0.12-0.23)$ and bleeding $(\mathrm{OR}=0.27 ; 95 \% \mathrm{CI}$, 0.16-0.43) compared with control (placebo, a cytoprotective agent, or an H2RA) ${ }^{64}$

A double-blind RCT (OMNIUM study) compared omeprazole and misoprostol for NSAID-induced ulcers. Although the two drugs were overall equally effective, remission rates were better with omeprazole $(61 \%$ vs $48 \%$; $\mathrm{p}=0.001)$. Moreover, omeprazole was better tolerated than misoprostol. ${ }^{65}$

A RCT comparing misoprostol with two doses of lansoprazole reported that both drugs were equally effective and superior to placebo. After considering the withdrawals due to AEs, treatment was deemed successful in 69\% of patients in each treatment group vs. $35 \%$ for placebo. ${ }^{66}$

A Cochrane review found that misoprostol significantly reduced the RR of gastric ulcer by $74 \%$ (RR, 0.26 ; $95 \% \mathrm{CI}, 0.17-0.39$ ) corresponding to a $12 \%$ absolute risk reduction. ${ }^{67}$ The review also reported that, while a standard dose of H2RA was effective at reducing the risk of endoscopic duodenal ulcer ( $R R=0.36$; $95 \% C I, 0.18-0.74)$, a double dose was required toreduce the risk of endoscopic gastric ulcer $(\mathrm{RR}=0.44 ; 95 \% \mathrm{CI}, 0.26-0.74) .{ }^{67}$

\section{Practice Recommendation 10}

There is no difference in effectiveness between different PPIs (esomeprazole, lansoprazole, omeprazole, pantoprazole, and rabeprazole) available in the market. All available PPIs at recommended doseshave similar efficacy in reducing the risk of NIG.

(Consensus: Vote; strongly agree $76 \%$, agree $24 \%$ )

\section{Rationale}

Few head-to-head studies are comparing the different PPIs in the managementof NIG. However, the available data suggest that all PPIs are essentially equivalentin the management of NIG. A randomized, double-blind study ( $\mathrm{N}=595)$ to compare pantoprazole (20 $\mathrm{mg}$ OD and 40 $\mathrm{mg}$ OD) withomeprazole (20 mg OD) for the prevention of GI lesions associated with NSAIDs found that both PPIs were similarly effective (remission rates for lack of "therapeutic failure" were $90 \%, 93 \%$, and $89 \%$, and for lack of "endoscopic failure" were $91 \%, 95 \%$, and $93 \%$ (for pantoprazole $20 \mathrm{mg} \mathrm{OD}$, pantoprazole $40 \mathrm{mg} \mathrm{OD}$, and omeprazole $20 \mathrm{mg}$ OD, respectively). ${ }^{68}$

A systematic review comparing the efficacy of different available PPIs found that for symptom relief in gastroesophageal reflux disease lansoprazole was faster than omeprazole, and esomeprazole was faster than both lansoprazole and omeprazole. However, none of thesedrugs was found to be superior over the other. ${ }^{69}$

A few novels or immediate-release formulations of PPIs have also been studied..$^{70}$ The immediate-release omeprazole $\left(\right.$ Zegerid $^{\circledR}$, Omez-Insta $^{\circledR}$ ) are associated with faster absorption of omeprazole, the more rapid onset of anti-secretory activity, and a slightly longer duration of acid suppression. This formulation is not food dependent and provides dosing flexibility which is considered apt for suppressing nocturnal gastric acid secretion. ${ }^{71}$ Immediate-release omeprazole has also shown superiority over once daily dosing of delayed-release PPIs in control of nocturnal gastric acidity. ${ }^{72}$ Dexlansoprazole is a PPI with adual delayed-release formulation, which produces a dual-peak pharmacokinetic profile unlike the single peak profile of the first generation or delayed release PPIs. Thus, dexlansoprazole maintains therapeutic plasma drug concentrations longer than lansoprazole and other PPIs. ${ }^{73}$

\section{Practice Recommendation 11}

It is suggested that physicians consider continued prophylaxis with a PPI when NSAIDs are prescribed. (Consensus: Vote; strongly agree 69\%, agree $31 \%$ )

\section{Rationale}

In a large international multicenter study $(\mathrm{N}=610)$, both omeprazole and misoprostol improved QoL in chronic NSAID users with NSAID-associated gastroduodenal lesions. However, omeprazole relieved gastrointestinal symptoms better than misoprostol. Hence, it is appropriate to co-prescribe a PPI in this patient group for prophylaxis as long as NSAIDs are prescribed and taken. ${ }^{74}$

Long-term PPI treatment is associated with betteroutcomes in patients continuing NSAID therapy. A large RCT in OA and RA patients compared omeprazole with ranitidine in the prevention of gastric and duodenal ulcers. Omeprazole healed and prevented ulcers more effectively than ranitidine over 8 weeks of the study. During the subsequent 6-month maintenance treatment, $72 \%$ and $59 \%$ of patients were in remission in the omeprazole and ranitidine groups respectively. Relapses were more common with ranitidine than with omeprazole. ${ }^{75}$

In long-term NSAID users, a PPI can substantially reduce the occurrence of GI complications. A 3-month 
studyto evaluate omeprazole $20 \mathrm{mg}$ every morning as primary prophylaxis against NSAID-induced ulcer and dyspepsia, found that the estimated probability of remaining symptom-free for 6 months for patients taking omeprazole was 0.78 compare $d$ to 0.53 for placebo $(\mathrm{p}=0.004) .{ }^{76}$ Thus, continuing a PPI is important in the management of NIG. Although long-term PPIs could be associated with some AEs, in patients with a clear indication for the PPI, the risk-benefit ratio favors PPI use. $^{43}$

\section{Practice Recommendation 12}

The following clinical presentations in a patient taking an NSAID to raise the suspicion of NIG: abdominal cramps/ pain, dyspepsia, nausea, and vomiting.

In patients with pre-existing risk factors for gastropathy, it is suggested that the physician maintain a high index of suspicion of onset of NSAID-induced gastropathy in patients on NSAID therapy developing such symptoms.

(Consensus: Vote; strongly agree $43 \%$, agree $40 \%$, disagree $9 \%$, and strongly disagree $9 \%$ )

\section{Rationale}

Upper GI symptoms including dyspepsia, heartburn, bloating or cramping, nausea, and vomiting are reported in up to $40 \%$ of patients taking NSAIDs. ${ }^{77}$ However, in 50 to $60 \%$ NSAIDs users, GI complications may be clinically asymptomatic. ${ }^{78}$ Hence, close monitoring is advisable forall patients on long-term NSAIDs, particularly those with the presence of one or more risk factors.

\section{Practice Recommendation 13}

It is suggested that to determine the risk, physicians take a careful history andperform necessary laboratory tests when starting NSAID treatment.

If a patient presents with a history, or clinical symptoms and signs suggesting NSAID-related GI problems, the PCP should consider referring the patient to a specialist for further management.

(Consensus: Vote; strongly agree $38 \%$, agree $54 \%$, disagree $16 \%$, and strongly disagree $2 \%$ )

\section{Rationale}

Standard approaches for diagnosing NIG include identification of high-risk populations; history, clinical presentation, and examination of the patient; tests for $H$. pylori infection in suspected cases; and hemoglobin and hematocrit tests. Upper GI endoscopy is required to confirm the diagnosis. ${ }^{79}$

\section{Practice Recommendation 14}

While PPIs are the preferred drugs, some choice of GPA (in treatment doses) is recommended for patients diagnosed with NIG.

(Consensus: Vote; strongly agree $40 \%$, agree $40 \%$, disagree $17 \%$, and strongly disagree $2 \%$ )

\section{Rationale}

Several studies have highlighted the efficacy of PPIs in the treatment of LDA- and NSAID-induced GI injury. ${ }^{63,64,80-82}$ Evidence also indicates that PPIs are superior to other GPAs. ${ }^{63-65,74,75}$ Therefore, PPIs remain the preferred treatment. Nevertheless, other GPAs, including H2RAs and misoprostol, have also demonstrated effectiveness in the treatment of $\mathrm{NIG}^{66,67,83,84}$ and may be considered when PPIs cannot be prescribed.

\section{Practice Recommendation 15}

A fixed-dose combination (FDC) of an NSAID and a GPA is not recommended in patients with NIG.

(Consensus: Vote; strongly agree 59\%, agree 28\%, disagree $13 \%)$

\section{Rationale}

The ketoprofen-omeprazole FDC was the first NSAID GPA combination to be approved. ${ }^{85}$ Other commonly used FDCs include ibuprofen-famotidine and naproxenesomeprazole. ${ }^{86,87}$ Although FDCs are believed to be associated with better compliance; sufficient clinical evidence is not available to support their superiority regarding efficacy and safety. ${ }^{86,87}$ Furthermore, the high-cost of FDC makes prescription difficult in long-term users, such as patients with OA.

Boxes 1 and 2 list the recommendations for doctors in the treatment of NIG for highrisk and moderate risk patients respectively.

\section{CONCLUSION}

NSAIDs are the most widely used drugs for controlling pain and inflammation. Easy availability (as OTC drugs) and good efficacy of these drugs increase their use. However, the gastrointestinal complications, particularly gastropathy, remain a matter of concern for the prescribing physician. The risks of developing gastropathy further increase with high-dose, long-term, or inappropriate use of NSAIDs especially in the elderly. Hence, recommendations are necessary to guide a PCP in making safe and sensible use of NSAIDs and to minimize the risk 
Box 1: Recommendations for doctors-high risk patients

1. Document patient's history and carry out necessary laboratory investigations before starting any treatment

2. For high-risk patients, avoid NSAIDs and use alternate management strategies like physiotherapy and/or exercise to ease pain and inflammation in diseases like $O A$

3. Consider prescribing low doses and shorter durations for diseases that require instant relief (headache, dysmenorrhea, post-operative pain)

4. Consider pulse therapy - prescribing large doses NSAIDs in an intermittent manner to enhance the therapeutic effect and reduce the $\mathrm{Gl}$ complications/other adverse events in chronic diseases

5. Avoid prescribing NSAIDs with other drugs (SSRIs, antiplatelet drugs, corticosteroids)

6. Inform the patient that NSAIDs can be taken "as required" and generally do not have a fixed schedule

7. Prefer selective COX-2 inhibitors like coxibs or safer drugs like amtolmentinguacyl over conventional NSAIDs

8. Prescribe double dose of gastroprotective agents like PPIs in patients undergoing long-term ( $>30$ days) NSAID treatment

9. Prescribe a single dose of PPI (up to 30 days) in patients undergoing NSAID treatment

10. Perform periodic assessment of patients on long-term NSAID therapy for early identification of signs/symptoms of gastropathy

Abbreviations: COX-2, cyclooxygenase-2; GI, gastrointestinal; NSAID, non-steroidal anti-inflammatory drug; OA, osteoarthritis; SSRI, selective serotonin reuptake inhibitor

of gastropathy. The Consensus Group recommends the use of NSAIDs only as and when indicated. Associated risk factors and a risk profile of the patient is important and should be determined before prescribing NSAIDs. Additionally, physicians are encouraged to take time to educate their patients about the safe use of NSAIDs properly, to avoid dose creep, and not combine their prescribed drugs with OTC medications without prior discussion with their physician. Furthermore, risk monitoring of patients undergoing long-term NSAID treatment and cotherapy with a GPA usually a PPI is also recommended. The consensus group emphasizes the importance of the patient's age, history, clinical presentation, and presence of H. pylori infection for timely management of NIG; and the need to develop clinical strategies to ensure GI safety for patients undergoing NSAID treatment.

\section{ACKNOWLEDGMENTS}

The consensus conference was supported by an unrestricted educational grant from Dr Reddy's Laboratories Ltd. We would like to thank all the clinicians who actively participated in the survey, discussions, and voting process. The names of all the voters are included in the appendix. The authors acknowledge Turacoz Healthcare Solutions (www.Turacoz.com), Gurugram, India, for helping in the conduct of survey, coverage of advisory board meeting, and writing support.
Box 2: Recommendations for doctors-moderate risk patients

1 Document patient's history and carry out necessary laboratory investigations before starting any treatment

2. Consider prescribing topical NSAIDs over oral NSAIDs in patients experiencing mild pain like muscle pain, or low back pain

3 Initiate prophylactic therapy with PPI (e.g. Omeprazole 20 $\mathrm{mg}$ once daily) to reduce the risk of gastropathy

4. Consider H. pylori eradication in case it was diagnosed, and eradication therapy not given

5. Include an antacid in the drug regimen as antacids neutralize existing stomach acid and can provide rapid pain relief

6. Consider probiotic supplement (containing Lactobacillus acidophilus). Probiotics or "friendly" bacteria may help maintain a balance in the digestive system between good and harmful bacteria

7. Suggest a multivitamin daily to improve digestive health (e.g. multivitamins containing the antioxidant vitamins A, C, $\mathrm{E}$, the $\mathrm{B}$ vitamins, and trace minerals, such as magnesium, calcium, zinc, and selenium)

8. Guide patients to avoid self-medication, high dose unregulated use of NSAIDs, and to never combine OTC medications without consultation

9. Counsel the patients well and educate them on the signs and symptoms of gastropathy so that they can reach for help at the earliest

10. Suggest the patients to visit regularly so that the need for further treatment with NSAIDs can be reviewed

Abbreviations: COX-2, cyclooxygenase-2; GI, gastrointestinal; NSAID, non-steroidal anti-inflammatory drug; OA, osteoarthritis; OTC, over-thecounter; SSRI, selective serotonin reuptake inhibitor

\section{Voting Participants}

\begin{tabular}{ll}
\hline Participant Name & Country \\
\hline Julia Gorgun & Belarus \\
Jan Tack & Belgium \\
Richard Hunt & Canada \\
G N Ramesh & India \\
Almagul Kuzgibekova & Kazakhstan \\
Yerlan Bazargaliyev & Kazakhstan \\
Gyuzel Jakupova & Kazakhstan \\
Baurzhan Iskakov Samikovich & Kazakhstan \\
Thein Saw & Myanmar \\
Win Phyu Phyu Myint & Myanmar \\
Khin San Aye & Myanmar \\
Paul Jurgen Porr & Romania \\
Elena-Tatiana Ivan & Romania \\
Radu-Bogdan Mateescu & Romania \\
Cristina Daniela Bura & Romania \\
Ligia Ariana Bancu & Romania \\
Victor-CatalinSfarti & Romania \\
Mircea Manuc & Romania \\
Lucian Negreanu & Romania \\
Elena Onuchina & Russia \\
\hline & \\
&
\end{tabular}


Contd...

\begin{tabular}{|c|c|}
\hline Participant Name & Country \\
\hline Mikhail Sheviakov & Russia \\
\hline Tatiana Sviridova & Russia \\
\hline Oksana Pozdniakova & Russia \\
\hline Elina Petrova & Russia \\
\hline Svetlana Turkina & Russia \\
\hline Elena Vyuchnova & Russia \\
\hline AimanSarsenbaeva & Russia \\
\hline Irina Kozlova & Russia \\
\hline Aleksandr Stepchenko & Russia \\
\hline Oleg Mironchev & Russia \\
\hline Alexey Okhlobystin & Russia \\
\hline Tatiana lankovaia & Russia \\
\hline Elena Li & Russia \\
\hline Inna Putintseva & Russia \\
\hline Zarina Galeeva & Russia \\
\hline Sergei Alekseenko & Russia \\
\hline Elena Miguskina & Russia \\
\hline EmiliyaYakovenko & Russia \\
\hline Elena Kashkina & Russia \\
\hline Leonid Lazebnik & Russia \\
\hline Natalia Bakulina & Russia \\
\hline Victor Pasechnikov & Russia \\
\hline Dmitry Bordin & Russia \\
\hline Anell Meyer & South Africa \\
\hline Reidwaan Ally & South Africa \\
\hline Bilal Bobat & South Africa \\
\hline Vasudevan Naidoo & South Africa \\
\hline Fritz Potgieter & South Africa \\
\hline Monique Marais & South Africa \\
\hline Hitendrakumar Bhaga & South Africa \\
\hline Sandie Thomson & South Africa \\
\hline Yurii Stepanov & Ukraine \\
\hline Olha Bondarenko & Ukraine \\
\hline Andriy Dorofyeyev & Ukraine \\
\hline Abror Khamraev & Uzbekistan \\
\hline Feruza Khamrabaeva & Uzbekistan \\
\hline
\end{tabular}

\section{REFERENCES}

1. Singh G. Gastrointestinal complications of prescription and over-the-counter nonsteroidal anti-inflammatory drugs: a view from the ARAMIS database. Arthritis, Rheumatism, and Aging Medical Information System. Am J Ther 2000 Mar;7(2):115-121.

2. Koffeman AR, Valkhoff VE, Çelik S, W't Jong G, Sturkenboom $\mathrm{MC}$, Bindels PJ, et al. High-risk use of over-the-counter non- steroidal anti-inflammatory drugs: a population-based crosssectional study. Br J Gen Pract 2014 Apr;64(621):e191-198.

3. Peura DA. Gastrointestinal safety and tolerability of nonselective nonsteroidal anti-inflammatory agents and cyclooxygenase-2-selective inhibitors. Cleve Clin J Med 2002;69(Suppl 1):SI31-139.

4. Harirforoosh S, Asghar W, Jamali F. Adverse effects of nonsteroidal antiinflammatory drugs: an update of gastrointestinal, cardiovascular and renal complications. J Pharm Pharm Sci 2013;16(5):821-847.

5. Lassen A, Hallas J, Schaffalitzky de Muckadell OB. Complicated and uncomplicated peptic ulcers in a Danish county 1993-2002: a population-based cohort study. Am J Gastroenterol 2006 May;101(5):945-953.

6. Chatterjee S, Dureja GP, Kadhe G, Mane A, Phansalkar AA, Sawant S, et al. Cross-Sectional Study for Prevalence of NonSteroidal Anti-Inflammatory Drug-Induced Gastrointestinal, Cardiac and Renal Complications in India: Interim Report. Gastroenterology Res 2015 Aug;8(3-4):216-221.

7. Straube S, Tramèr MR, Moore RA, Derry S, McQuay HJ. Mortality with upper gastrointestinal bleeding and perforation: effects of time and NSAID use. BMC Gastroenterol 2009 Jun;9(1):41.

8. Yeomans ND, Lanas AI, Talley NJ, Thomson AB, Daneshjoo $\mathrm{R}$, Eriksson, et al. Prevalence and incidence of gastroduodenal ulcers during treatment with vascular protective doses of aspirin. Aliment Pharmacol Ther 2005 Nov;22(9):795-801.

9. Takeuchi K. Pathogenesis of NSAID-induced gastric damage: Importance of cyclooxygenase inhibition and gastric hypermotility. World J Gastroenterol 2012 May;18(18):2147-2160.

10. Unified Clinical Protocol for Primary and Secondary Medical Care Peptic Ulcer of Stomach and Duodenum in Adults, Ukraine, 2014 Sep. Available at: http://mtd.dec.gov.ua/ images/dodatki/2014_613_PeptVyrazka_12paloi/2014_613y kpmd_PeptVyr.pdf.

11. Russian gastroenterological association clinical guidelines on diagnosis and treatment of NSAIDs-associated erosive and ulcerative lesions of the stomach and duodenum;2014. Available at: http://www.gastro.ru/userfiles/R_npvp_2014_6.pdf.

12. Abraham NS, Hlatky MA, Antman EM, Bhatt DL, Bjorkman DJ, Clark CB, Furberg CD, et al. ACCF/ACG/AHA. ACCF/ ACG/AHA 2010 Expert Consensus Document on the Concomitant Use of Proton Pump Inhibitors and Thienopyridines: A Focused Update of the ACCF/ACG/AHA 2008 Expert Consensus Document on Reducing the Gastrointestinal Risks of Antiplatelet Therapy and NSAID Use: a report of the American College of Cardiology Foundation Task Force on Expert Consensus Documents. Circulation 2010 Dec;122(24):2619-2633.

13. Lanza FL, Chan FK, Quigley EM. Practice Parameters Committee of the American College of Gastroenterology. Guidelines for prevention of NSAID-related ulcer complications. Am J Gastroenterol 2009 Mar;104(3):728-738.

14. NICE Guidelines: Acute upper gastrointestinal bleeding in over 16s: management. Available at: https://www.nice.org. uk/guidance/cg141.

15. Unified Clinical Protocol for Primary Medical Care Dyspepsia, Ukraine [August2012]. Available at: http://mtd.dec.gov.ua/ images/dodatki/2012_600/19_07_2012_ykpmd.pdf.

16. Rostom A, Moayyedi P, Hunt R. Canadian Association of Gastroenterology Consensus Group. Canadian consensus guidelines on long-term nonsteroidal anti-inflammatory drug 
therapy and the need for gastroprotection: benefits versus risks. Aliment PharmacolTher 2009 Mar;29(5):481-496.

17. Scarpignato C, Lanas A, Blandizzi C, Lems WF, Hermann M, Hunt RH, International NSAID Consensus Group. Safe prescribing of non-steroidal anti-inflammatory drugs in patients with osteoarthritis--an expert consensus addressing benefits as well as gastrointestinal and cardiovascular risks. BMC Med 2015 Mar;13:55.

18. Dalkey N, Helmer O. An Experimental Application of the DELPHI Method to the Use of Experts. Management Science. 1962 July;9(3):458-467

19. Hsu Chia-Chien, Sandford BA. The Delphi Technique: Making Sense of Consensus. Practical Assessment, Research \& Evaluation. 2007 Aug;12(10):1-8.

20. Lanas A, Boers M, Nuevo J. Gastrointestinal events in at-risk patients starting non-steroidal anti-inflammatory drugs (NSAIDs) for rheumatic diseases: the EVIDENCE study of European routine practice. Ann Rheum Dis 2015 Apr;74(4):675-681.

21. Schaffer D, Florin T, Eagle C, Marschner I, Singh G, Grobler $\mathrm{M}$, et al. Risk of serious NSAID-related gastrointestinal events during long-term exposure: a systematic review. Med J Aus. 2006 Nov;185(9):501-506.

22. Allison MC, Howatson AG, Torrance CJ, Lee FD, Russell RI. Gastrointestinal damage associated with the use of nonsteroidal anti-inflammatory drugs. N Engl J Med 1992; Sep 327(11):749-754.

23. GarcíaRodríguez LA, Barreales Tolosa L. Risk of upper gastrointestinal complications among users of traditional NSAIDs and COXIBs in the general population. Gastroenterology 2007 Feb;132(2):498-506

24. Hernández Díaz S, García Rodríguez LA. Association between nonsteroidal anti-inflammatory drugs and upper gastrointestinal tract bleeding/perforation. An overview of epidemiologic studies published in the 1990s. Arch Intern Med 2000 Jul;160(14):2093-2099.

25. García Rodríguez LA, Hernández-Díaz S. Relative risk of upper gastrointestinal complications among users of acetaminophen and nonsteroidal anti-inflammatory drugs. Epidemiology 2001 Sep;12(5):570-576.

26. Tarone RE, Blot WJ, McLaughlin JK. Nonselective nonaspirin nonsteroidal anti-inflammatory drugs and gastrointestinal bleeding: relative and absolute risk estimates from recent epidemiologic studies. Am J Ther 2004 Jan-Feb;11(1):1725.

27. Yeomans ND, Lanas AI, Talley NJ, Thomson AB, Daneshjoo R, Eriksson B, et al. Prevalence and incidence of gastroduodenal ulcers during treatment with vascular protective doses of aspirin. Aliment Pharmacol Ther 2005 Nov;22(9):795-801.

28. Derry S, Loke YK. Risk of gastrointestinal haemorrhage with long term use of aspirin: meta-analysis. BMJ 2000 Nov;321(7072):1183-1187.

29. Makris UE, Kohler MJ, Fraenkel L. Adverse Effects (AEs) of Topical NSAIDs in Older Adults with Osteoarthritis (OA): a Systematic Review of the Literature. J Rheumatol 2010 Jun;37(6):1236-1243.

30. Castellsague J, Riera-Guardia N, Calingaert B, Varas-Lorenzo C, Fourrier-Reglat A, Nicotra F, et al. Individual NSAIDs and upper gastrointestinal complications: a systematic review and meta-analysis of observational studies (the SOS project). Drug Saf 2012 Dec;35(12):1127-1146.

31. Huang JQ, Sridhar S, Hunt RH. Gastrointestinal safety profile of nabumetone: a meta-analysis. Am J Med 1999 Dec;107(6A):55S-61S; discussion 61S-64S.
32. Garg A, Shoeb A, Moodahadu LS, Sharma A, Gandhi A, Akku S. Amtolmeti: A Reappraisal of NSAID with Gastroprotection. Arthritis 2016;2016:7103705.

33. Fries JF, Williams CA, Bloch DA, Michel BA. Nonsteroidal anti-inflammatory drug- associated gastropathy: incidence and risk factor models. Am J Med 1991 Sep;91(3):213-222.

34. Koch M, Dezi A, Tarquini M, Capurso L. Prevention of nonsteroidal anti-inflammatory drug-induced gastrointestinal mucosal injury: risk factors for serious complications. Dig Liver Dis 2000 Nov;32(20):138-151.

35. Cardile S, Martinelli M, Barabino A, Gandullia P, Oliva S, Nardo GD, et al. Italian survey on non-steroidal anti-inflammatory drugs and gastrointestinal bleeding in children. World J Gastroenterol 2016 Feb;22(5):1877-1883.

36. Rafaniello C, Ferrajolo C, Sullo MG, Sessa M, Sportiello L, Balzano A, et al. Risk of gastrointestinal complications associated to NSAIDs, low-dose aspirin and their combinations: Results of a pharmacovigilance reporting system. Pharmacol Res 2016 Feb;104:108-114.

37. Lanas A, Benito P, Alonso J, Hernández-Cruz B, Barón-Esquivias G, Perez-Aísa Á, et al. Safe prescription recommendations for non-steroidal anti-inflammatory drugs: consensus document ellaborated by nominated experts of three scientific associations (SER-SEC-AEG). ReumatolCli. 2014 Mar-Apr;10(2): 68-84.

38. Lanas A, García-Rodríguez LA, Arroyo MT, Gomollón F, Feu F, González-Pérez A,et al. Risk of upper gastrointestinal ulcer bleeding associated with selective cyclo-oxygenase-2 inhibitors, traditional non-aspirin non-steroidal anti-inflammatory drugs, aspirin and combinations. Gut 2006 Dec;55(12):17311738 .

39. Delaney JA, Opatrny L, Brophy JM, Suissa S. Drug drug interactions between antithrombotic medications and the risk of gastrointestinal bleeding. CMAJ 2007 Aug;177(4):347-351.

40. Nagata N, Niikura R, Aoki T, Shimbo T, Kishida Y, Sekine K, et al. Lower GI bleeding risk of nonsteroidal anti-inflammatory drugs and antiplatelet drug use alone and the effect of combined therapy. GastrointestEndosc 2014 Dec;80(6):1124-1131.

41. Chang HY, Zhou M, Tang W, Alexander GC, Singh S. Risk of gastrointestinal bleeding associated with oral anticoagulants: population based retrospective cohort study. BMJ 2015 Apr;350:h1585.

42. Halperin D, Reber G. Influence of antidepressants on hemostasis. Dialogues Clin Neurosci 2007;9(1):47-59.

43. Scarpignato C, Gatta L, Zullo A, Blandizzi C; SIF-AIGOFIMMG Group; Italian Society of Pharmacology, the Italian Association of Hospital Gastroenterologists, and the Italian Federation of General Practitioners. Effective and safe proton pump inhibitor therapy in acid-related diseases - A position paper addressing benefits and potential harms of acid suppression. BMC Med 2016 Nov;14(1):179.

44. Mort JR, Aparasu RR, Baer RK. Interaction between selective serotonin reuptake inhibitors and nonsteroidal antiinflammatory drugs: review of the literature. Pharmacotherapy 2006 Sep;26(9):1307-1313.

45. Helin-Salmivaara A, Huttunen T, Grönroos JM, Klaukka T, Huupponen R. Risk of serious upper gastrointestinal events with concurrent use of NSAIDs and SSRIs: a case-control study in the general population. Eur J Clin Pharmacol 2007 Apr;63(4):403-408.

46. Anglin R, Yuan Y, Moayyedi P, Tse F, Armstrong D, Leontiadis GI. Risk of upper gastrointestinal bleeding with selective serotonin reuptake inhibitors with or without concurrent 
nonsteroidal anti-inflammatory use: a systematic review and meta-analysis. Am J Gastroenterol 2014 Jun;109(6):811819.

47. Oka Y, Okamoto K, Kawashita N, Shirakuni Y, Takagi T. Metaanalysis of the risk of upper gastrointestinal hemorrhage with combination therapy of selective serotonin reuptake inhibitors and non-steroidal anti-inflammatory drugs. Biol Pharm Bull 2014;37(6):947-953.

48. Sostres C, Gargallo CJ, Lanas A. Interaction between Helicobacter pylori infection, nonsteroidal anti-inflammatory drugs and/or low-dose aspirin use: old question new insights. World J Gastroenterol 2014 Jul;20(28):9439-9450.

49. Huang JQ, Sridhar S, Hunt RH. Role of Helicobacter pylori infection and non-steroidal anti-inflammatory drugs in pepticulcer disease: a meta-analysis. Lancet 2002 Jan;359(9300):1422.

50. Papatheodoridis GV, Sougioultzis S, Archimandritis AJ. Effects of Helicobacter pylori and nonsteroidal anti-inflammatory drugs on peptic ulcer disease: a systematic review. Clin Gastroenterol Hepatol 2006 Feb;4(2):130-142.

51. Vergara M, Catalán M, Gisbert JP, Calvet X. Meta-analysis: role of Helicobacter pylori eradication in the prevention of peptic ulcer in NSAID users. Aliment PharmacolTher 2005 Jun;21(!2):1411-1418.

52. Kono Y, Okada H, Takenaka R, Miura K, Kanzaki H, Hori K, et al. Does Helicobacter pylori Exacerbate Gastric Mucosal Injury in Users of Nonsteroidal Anti-Inflammatory Drugs? A Multicenter, Retrospective, Case-Control Study. Gut Liver 2016 Jan;10(1):69-75.

53. Pounder RE. Helicobacter pylori and NSAIDs--the end of the debate? Lancet 2002 Jan;359(9300):3-4.

54. Malfertheiner P, Megraud F, O'Morain CA, Gisbert JP, Kuipers EJ, Axon AT, et al. European Helicobacter and Microbiota Study Group and Consensus panel. Management of Helicobacter pylori infection-the Maastricht V/Florence Consensus Report. Gut 2017 Jan;66(1):6-30.

55. Fallone CA, Chiba N, van Zanten SV, Fischbach L, Gisbert JP, Hunt RH, et al. The Toronto Consensus for the Treatment of Helicobacter pylori Infection in Adults. Gastroenterology 2016 Jul;151(1):51-69.e14.

56. Warlé-van Herwaarden MF, Koffeman AR, Valkhoff VE, 't Jong GW, Kramers C, Sturkenboom MC, et al. Time-trends in the prescribing of gastroprotective agents to primary care patients initiating low-dose aspirin or non-steroidal anti-inflammatory drugs: a population-based cohort study. Br J Clin Pharmacol 2015 Sep;80(3):589-598.

57. Sebaldt RJ, Petrie A, Goldsmith CH, Marentette MA. Appropriateness of NSAID and Coxib prescribing for patients with osteoarthritis by primary care physicians in Ontario: results from the CANOAR study. Am J Manag Care 2004;10(11):742750.

58. Ray WA, Stein CM, Byrd V, Shorr R, Pichert JW, Gideon P, et al. Educational program for physicians to reduce use of non-steroidal anti-inflammatory drugs among communitydwelling elderly persons: a randomized controlled trial. Med Care 2001;39(5):425-435.

59. Lee SH, Han CD, Yang IH, Ha CW. Prescription Pattern of NSAIDs and the Prevalence of NSAID-induced Gastrointestinal Risk Factors of Orthopaedic Patients in Clinical Practice in Korea. J Korean Med Sci 2011 Apr;26(4):561-567.

60. Kovac SH, Saag KG, Curtis JR, Allison J. Association of healthrelated quality of life with dual use of prescription and over- the-counter nonsteroidal antiinflammatory drugs. Arthritis Rheum 2008 Feb;59(2):227-233.

61. van Soest EM, Valkhoff VE, Mazzaglia G, Schade R, Molokhia $\mathrm{M}$, Goldstein JL, et al. Suboptimal gastroprotective coverage of NSAID use and the risk of upper gastrointestinal bleeding and ulcers: an observational study using three European databases. Gut 2011;60:1650-1659.

62. Scarpignato C, Hunt RH. Nonsteroidal antiinflammatory drug-related injury to the gastrointestinal tract: clinical picture, pathogenesis, and prevention. Gastroenterol Clin North Am 2010 Sep;39(3):433-464.

63. Leontiadis GI, Sreedharan A, Dorward S, Barton P, Delaney B, Howden CW, et al. Systematic reviews of the clinical effectiveness and cost-effectiveness of proton pump inhibitors in acute upper gastrointestinal bleeding. Health Technol Assess 2007 Dec;11(51):iii-iv, 1-164.

64. Mo C, Sun G, Lu ML, Zhang L, Wang YZ, Sun X, et al. Proton pump inhibitors in prevention of low-dose aspirin-associated upper gastrointestinal injuries. World J Gastroenterol 2015 May;21(17):5382-5392.

65. Hawkey CJ, Karrasch JA, Szczepañski L, Walker DG, Barkun A, Swannell AJ, Yeomans ND. Omeprazole compared with misoprostol for ulcers associated with nonsteroidal antiinflammatory drugs. Omeprazole versus Misoprostol for NSAID-induced Ulcer Management (OMNIUM) Study Group. N Engl J Med 1998 Mar;338(11):727-734.

66. Graham DY, Agrawal NM, Campbell DR, Haber MM, Collis C, Lukasik NL, et al. Ulcer prevention in long-term users of nonsteroidal anti-inflammatory drugs: results of a double-blind, randomized, multicenter, active- and placebo-controlled study of misoprostol vs. lansoprazole. Arch Intern Med 2002 Jan;162(2):169-175.

67. Rostom A, Dube C, Wells G, Tugwell P, Welch V, Jolicoeur E, McGowan J. Prevention of NSAID-induced gastroduodenal ulcers. Cochrane Database Syst Rev 2002;4:CD002296.

68. Regula J, Butruk E, Dekkers CP, de Boer SY, Raps D, Simon L, et al. Prevention of NSAID-associated gastrointestinal lesions: a comparison study pantoprazole versus omeprazole. Am J Gastroenterol 2006;101(8):1747-1755.

69. Vakil N, Fennerty MB. Direct comparative trials of the efficacy of proton pump inhibitors in the management of gastrooesophageal reflux disease and peptic ulcer disease. Aliment Pharmacol Ther 2003 Sep;18(6):559-568.

70. Howden CW. Review article: immediate-release proton-pump inhibitor therapy--potential advantages Aliment PharmacolTher 2005 Dec;22 Suppl 3:25-30.

71. Castell D. Review of immediate-release omeprazole for the treatment of gastric acid-related disorders. Expert OpinPharmacother 2005 Nov;6(14):2501-2510.

72. Castell D, Bagin R, Goldlust B, Major J, Hepburn B. Comparison of the effects of immediate-release omeprazole powder for oral suspension and pantoprazole delayed-release tablets on nocturnal acid breakthrough in patients with symptomatic gastro-oesophageal reflux disease. Aliment Pharmacol Ther 2005 Jun;21(12):1467-1474.

73. Metz DC, Vakily M, Dixit T, Mulford D. Review article: dual delayed release formulation of dexlansoprazole MR, a novel approach to overcome the limitations of conventional single release proton pump inhibitor therapy. Aliment PharmacolTher 2009 May;29(9):928-937.

74. Yeomans N, Wilson I, Långström G, Hawkey C, Naesdal J, Walan A, et al. Quality of life in chronic NSAID users: a com- 
parison of the effect of omeprazole and misoprostol. Scand J Rheumatol 2001;30(6):328-334.

75. Yeomans ND, Tulassay Z, Juhasz L, Rácz I, Howard JM, van Rensburg CJ, et al. A comparison of omeprazole with ranitidine for ulcers associated with nonsteroidal anti-inflammatory drugs. Acid Suppression Trial: Ranitidine vs. Omeprazole for NSAID-associated Ulcer Treatment (ASTRONAUT) Study Group. N Engl J Med 1998 Mar;338(11):719-726.

76. Cullen D, Bardhan KD, Eisner M, Kogut DG, Peacock RA, Thomson JM, et al. Primary gastroduodenal prophylaxis with omeprazole for non-steroidal anti-inflammatory drug users. Aliment PharmacolTher 1998 Feb;12(2):135-140.

77. Brun J, Jones R. Non-steroidal anti-inflammatory drugassociated dyspepsia: the scale of the problem. Am J Med 2001 Jan;110(1A):12S-13S.

78. Armstrong $\mathrm{CP}$, Blower AL. Non-steroidal anti-inflammatory drugs and life threatening complications of peptic ulceration. Gut1987 May;28(5):527-532.

79. Schellack N. An overview of gastropathy induced by nonsteroidal anti-inflammatory drugs. S Afr Pharm J 2012;79(4): 12-18.

80. Sugano K, Choi MG, Lin JT, Goto S, Okada Y, Kinoshita $Y$, et al. LAVENDER Study Group. Multinational, doubleblind, randomised, placebo-controlled, prospective study of esomeprazole in the prevention of recurrent peptic ulcer in low-dose acetylsalicylic acid users: the LAVENDER study. Gut 2014;63(7):1061-1068.

81. Scheiman JM, Lanas A, Veldhuyzen van Zanten S, Baldycheva I, Svedberg LE, Nagy P. Effect of esomeprazole on gastroduodenal erosions in patients at increased gastrointestinal risk treated with low-dose acetylsalicylic acid: a post-hoc analysis of the OBERON trial. Int J Cardiol 2015 Mar;182:500502.

82. Hooper L, Brown TJ, Elliott R, Payne K, Roberts C, Symmons D.The effectiveness of five strategies for the prevention of gastrointestinal toxicity induced by non-steroidal anti-inflammatory drugs: systematic review.BMJ 2004 Oct;329(7472): 948.

83. Taha AS, Hudson N, Hawkey CJ, Swannell AJ, Trye PN, Cottrell J, et al. Famotidine for the prevention of gastric and duodenal ulcers caused by nonsteroidal antiinflammatory drugs. N Engl J Med 1996 May;334(22):1435-1439.

84. Van Groenendael JH, Markusse HM, Dijkmans BA, Breedveld FC. The effect of ranitidine on NSAID related dyspeptic symptoms with and without peptic ulcer disease of patients with rheumatoid arthritis and osteoarthritis. Clin Rheumatol 1996 Sep;15(5):450-456.

85. Gigante A, Tagarro I. Non-steroidal anti-inflammatory drugs and gastroprotection with proton pump inhibitors: a focus on ketoprofen/omeprazole. Clin Drug Investig 2012 Apr;32(4):221-233.

86. Weinblatt, Michael E, Genovese, Mark C, Kivitz, Alan J, et al. Efficacy, Safety And Tolerability Of HZT-501, Including Users Of Low-Dose Aspirin, A Single-Tablet Combination Of Ibuprofen-Famotidine: Results Of Two Phase 3 Trials. [abstract] Arthritis Rheum 2010 Oct;62(10)(Suppl 10):945.

87. Sostek MB, Fort JG, Estborn L, Vikman K. Long-term safety of naproxen and esomeprazole magnesium fixed-dose combination: phase III study in patients at risk for NSAID-associated gastric ulcers. Curr Med Res Opin 2011 Apr;27(4):847854. 